\title{
The fourth industrial revolution: personnel, business and state
}

\author{
Eugene Genkin ${ }^{1}$, Sergey Filin",*, Vladimir Velikorossov ${ }^{3}$, Zhamilya Kydyrova $^{4}$, and Kirill \\ Anufriyev ${ }^{5}$ \\ ${ }^{1}$ Plekhanov Russian University of Economics, Department of Management, 117997, Stremyanny \\ Lane, 36, Moscow, Russian Federation \\ ${ }^{2}$ Plekhanov Russian University of Economics, Department of Management, 117997, Stremyanny \\ Lane, 36, Moscow, Russian Federation \\ ${ }^{3}$ Plekhanov Russian University of Economics, Department of Management, 117997,Stremyanny \\ Lane, 36, Moscow, Russian Federation \\ ${ }^{4}$ M.Auezov South-Kazakhstan State University, 160012, Tauke Khan Ave, Shymkent, Kazakhstan. \\ ${ }^{5}$ Plekhanov Russian University of Economics, Department of Management, 117997, Stremyanny \\ Lane, 36, Moscow, Russian Federation
}

\begin{abstract}
The solved tasks are to develop recommendations for combining industry 4.0 technologies with the reduction of less qualified personnel due to their use while maximizing (keeping) of the efficiency of the organization's activities. The novelty is the justification for the need to use strategic methodological approaches for design and development of new value proposals and business models in the organization for the strategically effective use of Industry 4.0 technologies and management of highly qualified personnel. The main characteristics, basic technologies and the strategic role of Industry 4.0, as well as its impact on business and working conditions of employees and the state as a whole, are analyzed. The model of changes in the role of labor when using "digital" capital is analyzed. A full-fledged entry into Industry 4.0 will contribute to various structural and balance changes in the socio-economic sphere, while the main transformations will be subject to the traditional life of a person, his values, beliefs and, ultimately, the conditions of existence. Despite the fact that robotics in the course of Industry 4.0 to replace the individual, the human labour in specific segments will be necessary. Work is also necessary for the development of the individual, both culturally and psychologically.
\end{abstract}

\section{Introduction}

Since the beginning of the 2000s, the 4th industrial revolution (industry 4.0) began in the world. This is the era of advanced technologies based on information and communication [14]. They increase the level of competitiveness of companies when used correctly to create new factors of competitive advantage. Globalization together with the development of AI

\footnotetext{
${ }^{*}$ Corresponding author: Filin.SA@ rea.ru
} 
technologies is a prerequisite for the development of Industry 4.0. In turn, industry 4.0 technologies are becoming more integrated in their development, which promotes the modern global society to an information society with a digital economy. The process of globalization will accelerate in the course of Industry 4.0 and eventually this will affect working conditions and bring new risks.

\section{Results and Discussion}

\subsection{The impact of Industry 4.0 on working conditions}

Industry 4.0 implies a sharp reduction in the role of the individual in industrial activity, significantly changes the intellectual work of the individual, as a result of which the prospects for the development of the working environment are increasingly uncertain [5]. According to the us Department of labor, the number of workers in the industry decreased by $2 / 3$ from 1960 to 2014.at the same time, as technology has developed, productivity has increased dramatically, and in the field of intellectual activity, the growth has become non-linear. In addition, the creation of new industries requires an influx of higher-skilled labor and, as a result, the creation of qualitatively new jobs. Future jobs will be polarized depending on their nature and whether they can be automated or robotic. The impact of digital technologies reduces the share of labor in the final product. In recent years, the vast majority of economically developed and developing countries have significantly reduced the share of live labor in GDP due to the decrease in the cost of means of production, which increases the efficiency of replacing labor with capital. As a result, in Industry 4.0, suppliers of money capital and intellectual and knowledge capital in General - investors, shareholders and bankers, scientists and inventors-benefit. As a result, we can expect that the inequality between labor and capital income may deepen.

Industry 4.0 is likely to change the type of work performed, not just the number of jobs. For example, the role of marketers is changing due to the emergence of "big data", which is the main technology in Industry 4.0. Instead of market research based on the processing of current surveys, the possibility of rapid analysis of a huge array of accumulated data is growing. Therefore, when hiring, preference will be given to employees who possess technologies for collecting, storing, analyzing and distributing "big data" [6, 7]. Jobs that require repetitive tasks, such as mathematical operations, data classification, and management, are in danger of disappearing, and professions that are currently considered highly paid and stable (such as doctors, lawyers) are likely to be replaced by AI and robots.

With the growth of business platforms on the basis of AI's work force likely will be treated as content. For example, organizations like Uber or Airbnb can significantly reduce transaction costs by connecting service providers and consumers directly. They do not provide transportation and accommodation services by hiring employees or owning rental space. This approach worsens the working conditions of employees, increasing the fragmentation of jobs: "standard employment" (safe type of employment and "eight to five" work) will decrease, and non-standard employment, defined as jobs for freelancers, will increase significantly. Global business networks currently lead to the destruction of employees ' biorhythms, overwork, and other negative consequences. Social disunity due to self-employment will pose a risk to the employee's mental health. When robots replace people when performing simple and repetitive tasks, workers experience anxiety about employment and livelihoods.

In addition, automation introduced to improve productivity and quality of life can paradoxically lead to longer working hours or worse working conditions for an employee. For example, if the automation fails, the worker must repair it manually. At this time, you need to disable all equipment and ensure the safety of the employee. However, in many cases, 
safety checks are performed without stopping the equipment for maintenance, which is why most industrial accidents occur in this situation.

In an economy based on effective demand, workers are independent contractors, and it is difficult for them to get a guaranteed income because "demand" changes every day/hour. Therefore, employees must search for work as independent contractors on a daily/hourly basis, so that they bear the risk of income fluctuations, which was previously one of the main risks of organizations [8]. In this situation, employees cannot avoid stress and instability. Like most individuals with temporary jobs, workers in an economy based on effective demand rather than choice often choose to work on demand because they do not have a permanent job.

\subsection{Analysis of the model of changes in the role of labor in Industry 4.0}

The use of "digital" capital contributes to a significant increase in productivity and, consequently, the rate of economic growth. In connection with the growth of capital and labor productivity as a result, the parameters $\alpha$ and $\beta$ in the Cobb - Douglas function must obey the rule $[(\alpha+\beta)>1]$, which indicates a simultaneous increase in income from the use of labor and capital. The function shows the proportions of the contribution of labor and capital to the growth of production:

$$
Y=A \cdot K^{\alpha} \cdot L^{\beta}
$$

where $Y$ - the volume of production in the economy (national to move or GDP); $A$ - the coefficient that reflects the performance of the technologies; $K$ and $L$ - factors of production - capital and labour respectively; $\beta=(1-\alpha)$.

According to world statistics [9] greater use of digital capital through automation and reducing the use of simple and skilled labor, as well as the corresponding change of income of the owners of these factors in the long-term aspect is reflected in the formula (1): increases the value in the cumulative income share of capital $(\alpha)$ and remuneration of capital in connection with the growth of its contribution to the GDP, whereas the value $\beta(1-\alpha)$ (the remuneration of labor services corresponding to the contribution of this resource to GDP) falls. However, the decline in the share of the contribution of labor in GDP, and thus its reward is only with respect to the share capital, in absolute terms, the income of this factor is increased due to the following aspects: 1) based on the properties of the Cobb - Douglas function, at the equilibrium economic growth, the increased use of capital leads to an increase in marginal productivity of another factor - labour; 2) the overall increase in technology productivity in Industry 4.0 increases the marginal productivity of all factors of production, which allows more pay for more productive workers who replace low-paid low-skilled labor $[10,11] ; 3)$ reducing the costs of users and producers of digital products due to network effects leads to simultaneous expansion of demand and supply in sectors using digital technologies.

From the conditions of the Solow model, it follows that the growth of productivity and income leads to a real expansion of consumption and savings of the population. Increasing productivity and reducing costs usually encourages investment, which is facilitated by accelerating the pace of technology change. An increase in investment leads to an increase in the amount of capital per 1 employee (capital ratio). By increasing the speed of technology updates, the rate of capital retirement is also changing. At the same time, the increase in technology productivity does not reduce the capital ratio, which increases the volume of output per 1 employee (the growth rate of its productivity). These changes lead to the fact 
that the function in the Solow model shifts upwards, increasing the steepness of the slope (Fig. 1).

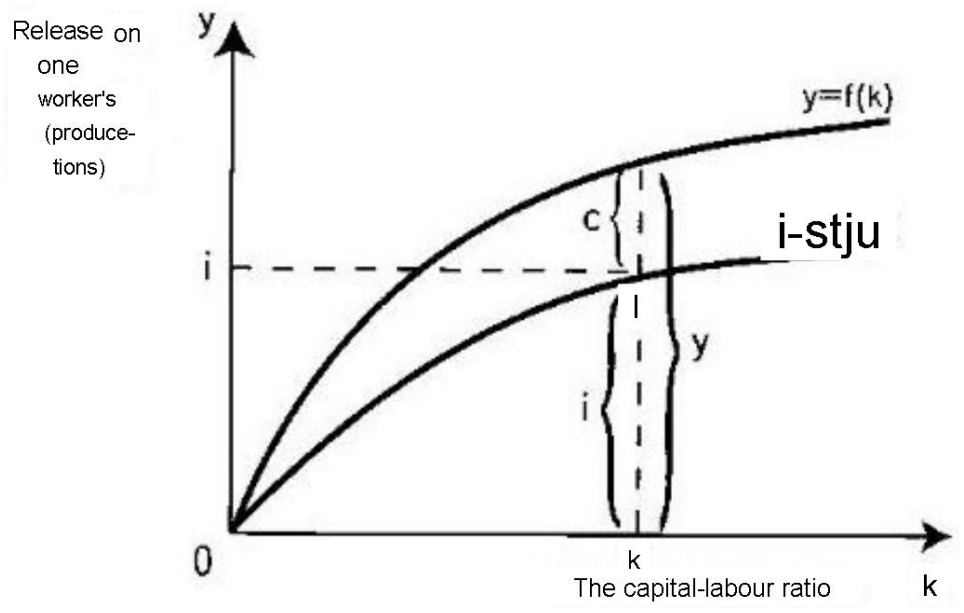

Fig. 1. Production function $(y=f(k)$, where $k=K / L$ - capital ratio), built on the basis of one employee and characterized by a decreasing marginal productivity of capital (MRK $=\delta+\mathrm{g}+\mathrm{n}$, where $\delta$ - the rate of capital retirement; $\mathrm{g}$ - the rate of technological progress; $\mathrm{n}$ - the rate of population growth).

\subsection{The impact of Industry 4.0 on business conditions}

Business Industry 4.0 by combining industrial and digital technology has had the most profound impact on: 1) ways of organizing and doing business, its marketing strategy; 2) resources; 3) network effects and economies of scale, transformed to the global; 4) production and transaction costs (organizational, managerial, communication, reception, processing and storage of information) in the digital sphere are reduced or disappear. This creates additional potential and new demands and requirements for the market, accelerate business and production. As a result, the life of the product and the company as a whole is reduced. For example, in the Standard \& Poor's 500 rating, the average life span of large corporations decreased from 60 to 18 years.

Digital technologies, including AI, and increased competition have created a trend of deepening relationships with customers through communication in the digital environment to identify and respond quickly to changes in their preferences. Solving client problems and client capital have become a source of additional income and simultaneously an acquired benefit in the inter-firm relations (B2B) segment. Real-time information and unique customer knowledge ensure high asset performance, which contributes to the company's further technological development. In Industry 4.0, work with the client is individualized, and engagement and empathy with their tasks are practiced. As a result, the probability of price discrimination increases, which is an additional source of profit for the company and an additional opportunity for the client. In making a profit, the focus shifts from selling a product to selling a service to use it, plus access to consumers almost globally.

Business and company cultures, in general, are changing towards the need for innovative leadership and self-perception in the structure of their organization (individual mental integration into the company), which implies the formation of an innovative culture in the company, the ability to generate and quickly implement effective innovative projects. Opportunities are expanded and project financing is accelerated, for example, by issuing tokens. 
3D and 4D printing technologies accelerate and optimize the availability of components that can be made individually by repair and Assembly companies. At the same time, companies are exempt from the costs of search, delivery, storage, and non-compliance with the required standard.

Competition between companies is moving from cost reduction to creativity, for example, through digital technologies and achieving high customer loyalty. It is also important to understand their preferences to work simultaneously in several industries, which allows them to use client bases, infrastructure and technologies at the intersectoral level, for example, the creation of telecommunications enterprises in motor transport and health care.

Artificial intelligence based on high-speed networks changes business processes. Business models based on big data analysis will be used everywhere. Digital technologies create transparency and new models of consumer behavior based on access to mobile networks and data. In response, companies adapt their development, marketing, and delivery methods and create new products and services. Using a combination of different technologies, companies are changing the forms and methods of doing business, getting the opportunity to create value in new market segments or find new centers of value creation in previous industries [12].

Business to a significant extent overcome the limitations of time and space and transformed into a common economic system.

Combining AI with cloud technologies and big data creates significant opportunities for companies and consumers. However, in order to use this potential, a global digital transformation is needed (in the narrow sense, the coverage of digital technologies for the production of goods and services) - a transition to more complex forms of innovation based on a combination of different technologies, which fundamentally changes existing business models [13]. This, in turn, requires the perception and introduction of new forms (innovative type) of thinking and doing business. Operational models are being transformed into new digital models, and business operations are being transformed into new forms and strategies.

An additional source of income is products of better quality, lower cost, and better service quality. By getting complete information about the mode of operation and wear, the business can monitor the continuous improvement of quality without replacing the product. Digital processing of data on the operation and condition of the product extends its use.

Technological innovations transform the perception and management of companies ' assets [14]. for example, remote software updates and network connectivity increase the value of used vehicles and aircraft, for example. Continuous monitoring of control indicators using sensors and algorithms helps to anticipate and eliminate the causes of emergencies in advance. Maintenance becomes a new quality, and special monitoring centers based on remote forecasting and new business models, such as outsourcing of non-strategically important or specialized industries, begin to deal with it. The company can extend the period of uninterrupted operation of equipment, the functionality of which is determined using analytics.

Collaborative innovation as a form of business collaboration allows you to combine resources, jointly implementing innovative projects, organize new forms of business based on sharing and storage, and so on. If a company lacks the capital, business knowledge, and customer base in a particular area that another firm has, and that, in turn, lacks digital skills in working with clients and the ability to quickly respond to changes in their requests. For example, enterprises of different industries, jointly serving customers, are combined for the common use of urban vehicles (integrated service). Such associations integrate the "office world" and the "online business world" through multilateral cooperation. The operating model for sharing is a digital platform based on the network effect when moving to the digital space. It brings together producers and consumers for joint use. By connecting to a carsharing company, for example, the customer receives mobility services without purchasing 
them, differentiated by the type and cost of the car and other individual requests in any place where there is a network. Research by the Massachusetts Institute of technology has shown that 14 of the 30 brands with the highest total market value in the world used platform strategies.

Using a platform with a deep knowledge of client requests makes the market transparent and more stable, but there may be problems: 1) reduced clarity in the property rights specification; 2) difficulty of choosing from an unlimited offer; 3 ) consistency of interaction with growing platforms that provide a wide range of services.

\subsection{Industry 4.0 and the government}

In a broader sense, digital transformation is a complex, multi-sided process that changes the structure and infrastructure of the economy and the entire range of socio-economic relations. Industry 4.0 is creating new state institutions whose development direction coincides with global trends in digital transformation, in particular, the transition of state systems to electronic management, which automates administrative tasks and makes it possible to provide services online.

Cloud organizations and courts are being formed in the digital business environment. For example, the Aragon project creates decentralized global companies that exist outside of country jurisdiction in the cloud. For business, this is a big saving on intra-company transactions, for the state-a problem with regulation and taxation. For example, in "cloud" arbitration, the program selects jurors from the blockchain community. They study the documentation and content of the conflict. The blocked disputed amount, depending on the verdict, remains on the defendant's account or is transferred to the plaintiff 's account. Companies changing their shape by moving to the digital space can solve their problems faster, potentially at a high expert level. Electronic code is not subject to bribery and lobbying. The regime of property rights becomes transparent and guaranteed, all other things being equal.

\subsection{Recommendations}

1. Companies in the era of Industry 4.0 should avoid investments that will not improve their market position. Therefore, it is necessary to have a strategic vision that allows you to identify new products/services that can be offered to the market, and the corresponding business models. New strategic methodological approaches are needed to develop and develop new value propositions and business models, primarily for management and organization. In order to use industry 4.0 technologies strategically effectively, it is necessary to have an understanding of the strategic, organizational, managerial, and cultural mechanisms that they can form. It is with this understanding that you can choose the most effective technologies to create more tools for a positive impact on the business and avoid reducing the return on investment when implementing projects. At the same time, it is necessary to know how to make the right changes, in particular, digital mechanisms, in the reference paradigms of management and risk management in the company [15]. Vertical ("strategic management - organization - technology - culture") and horizontally integrated ("machine - human") approaches to project implementation are also needed.

The company's operating model must be comprehensively analyzed in all aspects: structure, organization, management, culture, business processes and technologies used, etc. Thus, the following strategic opportunities can be used: a) the ability to innovate in the value proposition as a part of a product or service to produce and deliver "what is necessary, where necessary, and when necessary" ("on demand"); b) opportunities to change products in real time; offer customers services for joint design and production; work in an integrated and 
interactive mode with the business ecosystem ("open business") and in a "digital" mode at each management and operational level ("smart business»).

2. New technologies can be used to create a safe working environment by excluding employees from activities in harmful and dangerous conditions. For example, by using a deep learning algorithm to detect individual behavior patterns using surveillance cameras, you can track chemical leaks or industrial accidents in real time. If a dangerous situation is detected, the appropriate system can immediately alert the operator, safety officer, or responsible Department to prevent an accident. Using virtual reality technologies in training can improve the efficiency of the process.

Since multinational corporations use the shortcomings of labor laws in developing countries to increase productivity, workers in these countries work in dangerous jobs without adequate social security. Child and forced labour, which are prohibited in most developed countries, are common in developing countries. In this regard, it is necessary to introduce a global standard that defines the minimum acceptable working conditions.

In areas where there are not enough jobs, employment opportunities should be fair. In other words, it is necessary to discuss who will do a "decent" job and who will do a "bad" one.

Until now, "ideal" jobs have been seen as stable jobs where workers receive a fixed salary. However, as non-standard employment becomes popular, it is necessary to develop the concepts of stable and "good" jobs, "decent work" ("decent work").

3. According to the condition of maximizing consumption according to the "Golden rule of accumulation", the growth of equilibrium consumption is due to an increase in the rate of capital retirement and the rate of technical progress. Moreover, consumption is growing, although the rate of income growth is decreasing. Thanks to the technologies of the 6th technological order, it is possible to solve the problem-a combination of mutually exclusive goals of economic policy: to maximize / preserve the volume of consumption with a declining share of the labor force and an increasing share of the aging population. To do this, it is advisable to separately take into account the digital capital from human capital to allocate creative, which would more accurately determine the contribution of traditional and new factors of production to GDP growth. A model that takes into account changes in the structure and ratio of factors of production would allow us to assess changes in their shares in the total product and determine new proportions of remuneration for their owners.

\section{Conclusion}

Job insecurity is a complex and multifaceted problem. Even if a machine replaces an individual in the course of Industry 4.0, human labor in certain segments will undoubtedly be necessary. Work is also necessary for the development of the individual, both culturally and psychologically. Decent work should include many aspects: productivity, fair income and safety in the workplace, guarantees of social security for the family, individual selfdevelopment and social integration, and freedom of individual expression.

The main directions of changes in Industry 4.0 will be digitalization of processes, technological changes, as well as traditional human life, its values, beliefs and, ultimately, the conditions of existence.

\section{References}

1. J. Kang, J.-S. Kim, S. Seol, Foresight, v. 21, 6 (2019)

2. G. Li, Y. Hou, A. Wu, Chinese Geographical Science, v. 27, 4 (2017) 
3. L. Koh, G. Orzes, F. Jia, International Journal of Operations \& Production Management, v. 39, 5 (2019)

4. B. Ślusarczyk, M. Haseeb, H.I. Hussain, Engineering Management in Production and Services, v. 11, 2 (2019)

5. K.V. Gogolinskiy, V.A. Syasko, Insight: Non-Destructive Testing and Condition Monitoring, v. 61, 8 (2019)

6. N. Alias, W.M. Al-Rahmi, N. Yahaya, Q. Al-Maatouk, International Journal of Engineering and Technology(UAE), v. 7, 4 (2018)

7. J. Kim, International Neurourology Journal. T. 22. № 1 (2018)

8. N. Ventsel, Norwegian Journal of Development of the International Science, 18-3, (2018)

9. E. Brynjolfsson, E. McAfee, M. Spence, Foreign Affair, v. 93, 4 (2014)

10. V.A. Palkin, The Unity of Science: International Scientific Periodical Journal, 2 (2016)

11. M.R. Safiullin, L.A. Elshin, International Journal of Civil Engineering and Technology, v. 10, 2 (2019)

12. I. Kraftová, I. Doudová, R. Miláček, E \& M: Ekonomie a Management, v. 21, 3 (2018)

13. O.N. Yanitsky, International Journal of Media, Journalism and Mass Communications, v. 3, 2 (2017)

14. V.V. Velikorossov, Y.M. Bryukhanov, M.I. Maksimov, S.A. Filin, V.A. Kozlov1, A.K. Khudaibergenov, 2nd International Conference on Contemporary Education and Economic Development (CEED 2019) Beijing, China, (2019)

15. M.V. Khachaturyan, E.V. Klicheva, V.V. Velikorossov, International Conference on Politics, Economics and Management (ICPEM 2019), (2019) 